JURNALYOGA DAN KESEHATAN

JURUSAN YOGA KESEHATAN

FAKULTAS BRAHMA WIDYA

IHDN DENPASAR
Vol. 3 No. 1 Maret 2020

ISSN : 2621-0185 (Cetak)

http://ejournal.ihdn.ac.id/index.php/jyk

\title{
Efektivitas Hatha Yoga Terhadap Kesehatan Fisik
}

\section{Ni Wayan Yusi Armini ${ }^{1}$, Ida Ayu Diah Larashanti ${ }^{2}$}

Institut Hindu Dharma Negeri Denpasar

email : yusi.armini14@gmail.com,diahlarashanti20@gmail.com

Diterima tanggal 8 November 2019, diseleksi tanggal 9 Desember 2019, dan disetujui tanggal 27 Desember 2019

\section{ABSTRACT}

Today, humans are faced with life problems that are so tight with competition and competition in various aspects, so that it gives birth to a high tension culture. Tension that occurs causes disrupted anatomy of the body, even damage that causes balance of body and mind problems. This disharmony is a disease that many people face, namely stress, a psychosomatic disorder that can only be cured through inward healing, namely relaxation. Yoga is a method of self-discipline that has been applied and yoga also hits sports today, a sport that is very easy to use and at any time can and does not require a lot of space. So that yoga is made a healthy lifestyle trend that is not only recognized in the eastern hemisphere, especially for Hindus but also in the western world, which shows the universality of the teachings of Yoga itself that can be applied by anyone. One type of yoga that is famous in the world is Hatha Yoga. Hatha Yoga is one way of connecting with Iswara (God Almighty) by forming perfect harmony between the two pranic streams found in the body through the practice of Asana, Pranayama, Mudra and Bandha. So that Hatha Yoga is able to provide relaxation to the body and mind that will create physical and spiritual health.

Keywords: Hatha Yoga, Physical Health

\section{ABSTRAK:}

Dewasa ini, manusia dihadapkan pada persoalan hidup yang begitu ketat dengan persaingan dan kompetisi berbagai aspek, sehingga melahirkan budaya tegangan tinggi. Ketegangan yang terjadi menyebabkan anatomi tubuh terganggu, bahkan terjadi kerusakan yang menyebabkan keseimbangan tubuh dan pikiran bermasalah. Ketidakharmonisan ini menjadi penyakit yang banyak dihidapi masyarakat, yaitu stress, sebuah gangguan psikosomatis yang hanya dapat disembuhkan melalui penyembuhan ke dalam, yaitu relaksasi. Yoga merupakan suatu metode disiplin diri yang sudah di terapkan dan yoga juga olahraga hits masa kini, olahraga yang sangat mudah digunakan dan kapan saja bisa serta tidak membutuhkan banyak tempat. Sehingga yoga di jadikan tren pola hidup sehat yang tidak hanya di akui pada belahan dunia timur khususnya bagi umat Hindu tetapi juga di dunia bagian barat, yang menunjukkan ke universalan ajaran Yoga itu sendiri yang dapat di terapkan oleh siapa saja. Salah satu jenis yoga yang terkenal di dunia adalah Hatha Yoga. Hatha Yoga adalah salah satu jalan dalam menghubungkan diri dengan Iswara (Tuhan Yang Maha Esa) dengan membentuk keselarasan yang sempurna antara kedua aliran prana yang terdapat pada tubuh melalui latihan Asana, Pranayama, Mudra dan Bandha. Sehingga Hatha Yoga mampu memberikan relaksasi terhadap tubuh maupun pikiran yang akan menciptaan kesehatan jasmani dan rohani.

Kata kunci : Hatha Yoga, Kesehatan Fisik 


\section{PENDAHULUAN}

Yoga merupakan sebuah ilmu yang menjelaskan kaitan antara fisik, mental, dan spiritual manusia untuk mencapai sistem kesehatan menyeluruh (holistik) yang terbentuk dari kebudayaan India kuno. Yoga adalah penyatuan dari bahasa sansekerta atau bisa disebut juga dengan penyatuan alam. Secara teoretis Yoga berasal dari suku kata "yuj” yang memiliki menyatukan atau menghubungkan diri dengan Tuhan. Kemudian Patanjali memberikan definisi tentang yoga yaitu mengendalikan gerak-gerak pikiran (Somwir, 2009:23). Sedangkan menurut Swami Satya Nanda Saraswati (2002:1) menyebutkan yoga adalah pengalaman dari keutuhan atau kesatuan dengan keberadaan batin. Kesatuan itu muncul setelah menghancurkan dualitas pikiran dan masalah ke dalam kesadaran diri. Yoga adalah enam dari filsafat hindu dan aktivitasnya berupa meditasi mengerahkan panca indranya dan pikiran secara menyeluruh. Bahkan yoga bisa djadikan pengobatan alternative dilakukannya pemanasan, olah tubuh atau meditasi. Yoga adalah aktivitas gerakan olah tubuh dan juga pikiran yang sangat focus pada kekuatan dan pernapasan untuk meningkatkan kualitas mental dan fisik. Postur, rangkaian gerakan dan pernafasan adalah komponen utama yoga.

Berdasarkan pengertian di atas dapat disimpulkan yoga bersifat universal sehingga setiap praktisi memiliki berbagai pandangan dalam memahami yoga sebagai realisasi sang diri. kemudian untuk keseimbangan dalam menjalani hidup serta untuk kesehatan jasmani dan rohani semuanya akan bertemu pada satu tujuan yang sama yaitu mencapai kebahagiaan lahir dan batin. Selain itu tujuan melakukan praktek yoga telah dijabarkan Dalam kitab Manawa Dharmasastra II. 100 sebagai berikut :

Indriyasamyamasya sarwe purushartha hekutam daryacat : wace krtwendriya gramam samayam ya ca manasthatha, sarwan samsa dhayed artha na ksinwanyogatastanum

Terjemahan :

Kalau ia selalu mengendalikan kesepuluh alat indriyanya itu, seperti halnya juga dengan pikiran itu dikendalikan, ia akan dapat memproleh semua apa yang ia tuju tanpa mengurangi badannya dengan cara melakukan yoga. (Pudja dan Rai Sudharta,2002:89)

Petikan sloka di atas memaparkan bahwa yoga mengajarkan cara mengontrol indriya dan melihat ke dalam diri. Semakin sering seseorang mempraktekan yoga yang dijadikan bagian dari kebutuhan hidupnya maka akan mampu melihat ke dalam, dan ketenangan batinnya akan diproleh serta tidak akan terpengaruh terhadap hal-hal yang bersifat negatif . Kalau kita cermati lebih dalam, kebahagiaan manusia pada hakekatnya bersemayam dalam dirinya tetapi seringkali manusia tidak menyadari hal tersebut sehingga mereka mencari kebahagiaan di luar dirinya. Hal 
inilah yang harus disadari dalam yoga, sehingga ego akan terkikis dengan sendirinya kita akan menemukan kebahágiaan sejati dalam hidup.

Keindahan tubuh dalam melakukan asana yang dipercantik dengan mudra yang menyebabkan yoga memiliki daya tarik sendiri, sehingga pemahaman akan esensi yoga sesungguhnya perlu di pertahankan, agar tidak memaknai yoga hanya sekedar olah tubuh saja. Sesungguhnya yoga memiliki dasar nilai kebenaran, kesucian dan keindahan didalamnya yang dikenal dalam estetika hindu sebagai konsep satyam, sivam dan sundaram yang menunjukkan yoga berbeda dengan seni olah tubuh lainnya. Maka dari itu peneliti hanya focus akan membahas tentang efektivitas hatha yoga terhadap kesehatan fisik. Fisik atau dalam bahasa inggris "body" adalah sebutan yang berarti sesuatu wujud dan dapat terlihat oleh kasat mata, yang juga merupakan terdefinisi oleh pikiran.

\section{PEMBAHASAN}

\subsection{Definisi Efektivitas dan Makna Hatha Yoga}

Kata efektif berasal dari bahasa inggris effective artinya berhasil, sesuatu yang dilakukan berhasil dengan baik. Menurut teori efiktivitas merupakan suatu keadaan yang menunjukkan tingkat keberhasilan atau pencapaian suatu tujuan yang diukur dengan kualitas, kuantitas dan waktu sesuai dengan yang telah direncanakan sebelumnya. Menurut salah satu ahli menyebutkan bahwa efektivas juga merupakan suatu kegiatan yang dilaksanakan dan memiliki dampak serta hasil sesuai dengan yang diharapkan (Wiyono. 2007:137).

Kamus ilmiah populer mendefinisikan efetivitas sebagai ketepatan penggunaan, hasil guna atau menunjang tujuan. Pendapat H. Emerson yang dikutip Soewarno Handayaningrat S. (1994:16) yang menyatakan bahwa "Efektivitas adalah pengukuran dalam arti tercapainya tujuan yang telah ditentukan sebelumnya." Hal ini sesuai dengan pendapat yang dikemukakan oleh Hidayat (1986) yang menjelaskan bahwa :"Efektivitas adalah suatu ukuran yang menyatakan seberapa jauh target (kuantitas, kualitas dan waktu) telah tercapai. Dimana makin besar persentase target yang dicapai, makin tinggi efektivitasnya”. Dari beberapa pendapat di atas mengenai efektivitas, dapat disimpulkan bahwa efektivitas adalah suatu ukuran yang menyatakan seberapa jauh target (kuantitas,kualitas dan waktu) yang telah dicapai oleh manajemen, yang mana target tersebut sudah ditentukan terlebih dahulu. Sedangkan Efektivitas menurut H. Emerson : pengukuran dalam arti tercapainya sasaran atau tujuan yang telah ditentukan sebelumnya. (Soewarno Handayaningrat, 1990, hal 15) 


\subsection{Makna Hatha Yoga}

Di Amerika Serikat, penduduknya menyukai yoga dengan jenis Hatha. Hatha pertama kali diperkenalkan oleh Yogi (sebutan untuk praktisi yoga) Swatmarama di India pada abad ke15 dan dijelaskan oleh dia sebagai tangga ke puncak Raja yoga (Raja menjadi salah satu dari enam sekolah ortodoks filsafat Hindu, digarikan oleh Patanjali dalam Yoga Sutra) dan tahap persiapan untuk pemurnian fisi yang lebih tinggi. Hatha di kalangan dan jenis yoga satu ini sangat cocok dilakukan bagi pemula. Gerakan Hatha yoga adalah menekankan pada teknik asanas (postur), pranayama (olah nafas), bandha (kuncian), serta mudra (gesture). Jenis hatha yoga meliputi latihan fisik yang ringan, melibatkan setiap sendi pada tubuh dalam gerakan yang memperkuat, melonggarkan, dan menyeimbangkan setiap anggota tubuh.

Hatha adalah pengantar untuk yoga karena menggabungkan banyak asana yang berbeda, serta pranayama dan nyanyian. Banyak yogi percaya bahwa Hatha yoga merupakan cara yang paling bagus untuk meregangkan, bekerja pada otot sangat maksimal, dan dapat berhubungan langsung dengan tubuh yang membuat Anda lebih rileks dan mampu mengurangi rasa stres. Diterjemahkan dari bahasa Inggris-Yoga Haṭa adalah cabang dari yoga. Kata Sanskerta $\square \square$ hatha secara harfiah berarti "kekuatan" dan dengan demikian menyinggung sistem teknik fisik. Di India, hața yoga dikaitkan dalam tradisi populer dengan para Yogi Natha Sampradaya melalui pendiri tradisionalnya Matsyendranath.

Secara teoritis yoga termuat sebagai salah satu ajaran filsafat Hindu yang disebut Darsana. Kata Darsana berasal dari akar kata drś yang bermakna "melihat", menjadi kata darśana yang berarti "penglihatan" atau "pandangan". Kemudian diartikan sebagai pandangan tentang kebenaran. Tujuan Darśana adalah memperkuat pemahaman terhadap ajaran suci yang terkandung dalam Veda. Dengan mendalami Darśana melalui wahyu Maharsi, akan memberikan pencerahan (kejernihan) dalam mendalami dan mengamalkan ajaran Veda. Suamba (2003:77) menegaskan dalam Darsana terdiri atas enam pandangan tentang kebenaran (Sad Darśana). Termasuk yoga di dalamnya. Ajaran Yoga dibangun oleh Maharsi Patanjali, dan merupakan ajaran yang sangat populer di kalangan umat Hindu. Maharsi Patanjali mengartikan yoga sebagai Cittavrttinirodha yaitu penghentian gerak pikiran. Kitab Yogasutra, yang terbagi atas empat bagian dan secara keseluruhan mengandung 194 sutra. Bagian pertama disebut: Samadhipada, sedangkan bagian kedua disebut: Sadhanapada, bagian ketiga disebut: Vibhutipada, dan yang terakhir disebut: Kailvalyapada.

Kata Yoga, berasal dari bahasa Sansekerta, berasal dari kata 'yuj'yang artinya bersatu, (Suamba, 2003:362). Pandangan lainnya "Yoga adalah bentuk spiritual disiplin diri yang mempromosikan pencerahan dan akhirnya Samadi, yaitu sebuah akhir titik perjalanan yoga di 
mana kesadaran tersebut terhenti dan energi sepenuhnya diarahkan ke ruang obyek perhatian", (Kamajaya, 1998:20). Yoga adalah penghubungan, pengaitan atau persatuan jiwa individuil dengan Beliau Yang Maha Esa, Mutlak dan Tak Terbatas (Saraswati, Tanpa Tahun:1).

Tujuan akhir dari Yoga adalah moksha (pembebasan), meskipun demikian definisi yang tepat dari apa yang membentuk kata yoga ini tergantung pada sistem filosofis atau teologisnya. Menurut Jacobsen (2016:4) "Yoga memiliki lima makna pokok: (1)Yoga sebagai metode disiplin untuk mencapai tujuan; (2) Yoga sebagai teknik mengendalikan tubuh dan pikiran; (3) Yoga sebagai nama salah satu sekolahatau sistem filsafat (Darsana); (4) Yoga sehubungan dengan kata lain, seperti hatha yoga, mantra yoga, dan laya yoga, dan lainnya yang mengacu pada tradisi yang mengkhususkan diri dalam teknik yoga tertentu; (5) Yoga sebagai tujuan latihan yoga".

Menurut White (2014), pada abad ke-5 dan seterusnya, definisi dan prinsip-prinsip inti dari yoga memiliki variasi dalam berbagai bentuk, diantaranya; (1) Yoga sebagai analisis persepsi dan kognisi; prinsip ilustrasi ini ditemukan dalam teks-teks Hindu seperti Bhagavad Gita dan Yoga Sutra, serta sejumlah Buddha Mahayana; (2) Yoga sebagai awal dan perluasan kesadaran; ini dibahas dalam sumber-sumber Hindu seperti Epik Mahabharata, Jainisme Praśamaratiprakarana; (3) Yoga sebagai jalan untuk kemahatahuan; contoh ditemukan dalam agama Hindu Nyaya dan Vaisesika teks sekolah serta teks agama Buddha Madhyamaka, tetapi dengan cara yang berbeda; (4) Yoga sebagai suatu teknik untuk masuk ke dalam tubuh lainnya, menghasilkan beberapa sikap badan, dan pencapaian prestasi supranatural lainnya; ini dijelaskan dalam literatur Tantra Hindu dan Buddha, serta Budha Sāmaññaphalasutta. White menjelaskan bahwa prinsip terakhir berkaitan dengan tujuan legendaris "praktik yogi", yang berbeda dari tujuan praktis "latihan yoga," seperti yang dilihat dalam pemikiran Asia Selatan dan praktek sejak awal Masehi, di berbagai sekolah filsafat Hindu, Budha , dan Jain. Secara jelas yoga dapat diterangkan sebagai proses dan teknik untuk mengendalikan dan mengatur tubuh, pikiran serta hati, secara obyektif melalui disiplin spiritual, serta proses penyatuan antara kesadaran unit (diri) dan kesadaran kosmik (Tuhan). Yoga mencakup seluruh aplikasi yang inklusif dan universal yang mengantar kepada pencarian makna, integritas, dan stabilitas seluruh body, mind, and soul.

Selanjutnya penelitian Cramer (2014:1) juga menyebutkan hal yang sama terdiri terdapat (8) delapan tahapan yoga, sebagai berikut:

Yoga is rooted in Indian philosophy and has been a part of traditional Indian spiritual practice for millennia. The Indian sage Patañjali prescribed adherence to eight limbs of yoga, aimed at quieting one's mind to achieve the union of mind, body and spirit that is traditional yoga's ultimate goal. These limbs include 
'Yama' and 'Niyama' (a code of conduct for an ethical lifestyle), 'Asana' (physical postures), 'Pranayama' (breath control), 'Pratyahara' (withdrawal of the senses from external objects to increase self-awareness), 'Dharana' (concentration), 'Dhyana' (meditation) and 'Samadhi' (oneness with the object of meditation). Regardless of its spiritual origins, yoga has become a popular route to physical and mental well-being and has been adapted for use in complementary and alternative medicine in Western society. In the latter setting, yoga is most often associated with physical postures, breath control and meditation; and different yoga schools have emerged that put varying focus on physical and mental practices.

Secara terperinci metode pembelajaran yoga yang dilaksanakan di India, dikenal dengan delapan prinsip yang disebut dengan Astangga Yoga. Secara otentik pengetahuan ini dijabarkan pada Yoga Sutra Patanjali, mencerminkan tahapan pembelajaran yoga pada kehidupan manusia seutuhnya. Suamba, (2003:364) menjelaskan delapan tahapan yoga secara komprehensip.

Restorative yoga learning merupakan salah satu bentuk yoga bersifat lebih lentur atau gentle. Dan sering diidentikan dengan yin yoga, yoga nidra atau hatha yoga. Secara teoritis praktek yoga restoratif masih berada pada tahapan asana namun sudah bergerak pada tahapantahapan berikutnya. Baik, itu pranayama sampai pada samadhi. Proses belajar yoga restoratif dibuka untuk ruang-ruang dalam diri individu menjadi lebih nyaman dan damai.

\subsection{Manfaat Hatha Yoga Terhadap Kesehatan Fisik}

Tubuh manusia pada dasarnya diciptakan tidak stabil. Ini terkait dengan postur dan tinggi badan. Mempertahankan posisi tegak dan melaju bergerak dari satu tempat ke tempat sambil tetap seimbang adalah sebuah kerja keras tanpa henti bagi tubuh. Keberhasilan kita berjalan mulus tanpa terjatuh, tergantung pada kesehatan fisik dan peleburan kerja sistem yang berbeda dalam tubuh kita. Agar kita dapat mempertahankan keseimbangan, ada tiga sistem utama yang berperan menyediakan berbagai informasi sensorik mengenai kondisi tubuh, gravitasi, dan juga situasi lingkungan sekitar. Tiga sistem ini adalah visual (mata), vestibular (telinga), dan somotosensori (reaksi umpan balik dari persendian organ penggerak tubuh). Demi menjaga keseimbangan tubuh, otak harus cepat tanggap dalam menyatupadukan, mengolah, dan menyimpan semua informasi sensorik dari ketiga sistem tersebut, dan ini terus menerus dilakukan tanpa henti. Proses bawah sadar ini kemudian menciptakan respons motorik dan sistem otot yang terprogram berdasarkan pengalaman untuk membentuk pola pergerakan kita sehari-hari. 
Jatuh terjadi ketika tubuh dan otak kewalahan memproses tuntutan untuk mempertahankan posturnya. Jatuh dapat terjadi ketika pola pergerakan tubuh anda jadi terganggu atau berubah tiba-tiba akibat bahaya yang tak terduga. Hal ini dibuktikan oleh tim peneliti dari Massachusetts Eye and Ear Hospital dalam percobaan yang melibatkan 105 orang berusia 18-80 tahun. Setelah para peserta mengikuti beragam tes fisik dan uji keseimbangan, hasil studi melaporkan bahwa ambang batas toleransi minimum dari sistem vestibular pada orang-orang berusia 40 tahun ke atas meningkat secara drastis.

Sistem ventribular adalah sistem kompleks di telinga bagian dalam yang berfungsi layaknya navigator GPS, guna mendeteksi orientasi tubuh dalam ruangan berdasarkan gerakan dan posisi kepala, seperti saat kita sedang duduk, berdiri, tidur, dan lain sebagainya. Sistem inilah yang kemudian berkolaborasi dengan otak dan mata untuk mengatur keseimbangan, koordinasi, serta kontrol pergerakan tubuh. Umumnya, semakin rendah ambang batas vestibular seseorang, tubuh akan semakin baik dalam menjaga keseimbangannya. Dengan demikian, jika sistem ini rusak atau ambang batasnya meningkat, kita akan terlihat seperti orang mabuk, goyah sempoyongan dan mudah jatuh.

Seiring bertambahnya usia, proses bawah sadar demi menjaga keseimbangan tubuh mungkin tidak bekerja dengan baik atau tidak secepat seperti dulu. Dengan kata lain, ketajaman kognitif otak kita menumpul. Akibatnya, upaya mempertahankan keseimbangan mungkin membutuhkan konsentrasi mental yang lebih besar lagi, yang efeknya terbukti melelahkan. Kognitif otak yang menurun juga dapat membatasi kemampuan kita untuk multitasking. Ini sebabnya kita mungkin menyadari kalau orang-orang tua sering mendadak berhenti berjalan saat sedang bicara yang mencerminkan kesulitan ini.

Selain itu, penuaan juga membuat kualitas informasi sensorik yang disediakan oleh ketiga sistem keseimbangan tubuh kita jadi menurun.Penglihatan memburuk, ditambah dengan mata yang rentan cahaya silau dan persepsi kedalaman dimensi visual yang miskin. Hal ini dapat menyebabkan Anda keliru menafsirkan letak lantai, atau salah mengira jarak, sehingga membuat kita mudah jatuh.

Umpan balik somotosensori normal dari persendian kita ke otak juga ikut berkurang karena fleksibilitas juga menurun seiring usia menua. Penyakit kronis di persendian penahan berat (pinggul dan lutut), seperti artritis, dapat menyebabkan error penempatan kaki. Sementara itu, pola gerak kaki yang tidak selaras, kaki yang terasa sakit, dan/atau kebiasaan memakai sepatu berkualitas buruk dapat membuat otak salah menilai sinyal informasi tentang karakteristik kontak Anda dengan tanah ketika kita berjalan. Hidup serba mager alias malas gerak, lama kelamaan menyebabkan penurunan kekuatan fisik dan kepadatan tulang, sehingga keseimbangan 
tubuh lebih mudah goyah. Kelemahan tubuh ini juga membuat kita membutuhkan waktu yang lebih lama untuk bangkit dari jatuh. Lagi-lagi ini dikarenakan oleh penurunan fungsi otak, akibat kurangnya aktivitas fisik.

\section{KESIMPULAN}

Yoga merupakan salah satu olahraga tren saat ini yang banyak diminati oleh kalangan masyarakat baik tingkat anak-anak, remaja, dewasa dan bahkan lanjut usia (lansia). Yoga yang memberikan dampak positif bagi kesehatan fisik karena yoga bukan hanya sekedar olah tubuh saja namun juga miliki dasar nilai kebenaran, kesucian dan keindahan didalamnya yang dikenal dalam estetika hindu sebagai konsep satyam, sivam dan sundaram yang menunjukkan yoga berbeda dengan seni olah tubuh lainnya. Hatha yoga merupakan suatu pengantar yoga karena menggabungkan banyak asana yang berbeda, serta pranayama dan nyanyian. Banyak yogi percaya bahwa Hatha yoga merupakan cara yang paling bagus untuk meregangkan, bekerja pada otot sangat maksimal, dan dapat berhubungan langsung dengan tubuh yang membuat kita lebih rileks dan mampu mengurangi rasa stres. Yoga mampu memberikan dampak positif terhadap tubuh manusia dalam mengatasi penyakit baik itu melalui fisik maupun non fisik, sehingga terciptanya tubuh dan pikiran yag sehat.

\section{DAFTAR PUSTAKA}

Saraswati, Swami Satya Prakas, Tanpa Tahun. Patanjali Raja Yoga, Surabaya: Penerbit Paramita

Saraswati, Swami Satyananda, 2002. Asana, Pranayama, Mudra, dan Banda, Surabaya: Penerbit Paramita.

Suamba, I.B. 2003.Dasar-Dasar Filsafat India. Denpasar: Program Magister Ilmu Agama Dan Kebudayaan Universitas Hindu Indonesia Indonesia bekerjasama dengan Widya DharmaWijaya, A.A. Prima Surya, 2010. Memahami Catur Marga Empat Jalan Mencapai Tuhan, Surabaya: Penerbit Paramita.

Kamajaya, Gede, 1998. Yoga Kundalini (Cara Untuk Mencapai Siddhi dan Moksa), Surabaya: Penerbit Paramita.

Jacobsen. 12 Januari2016. Yoga. (Online).

https://en.wikipedia.org/wiki/Yoga\#cite_note-Jacobsen4-32, diakses 16 Januari 2016.

White, David Gordon (2014), The "Yoga Sutra of Patanjali": A Biography, Princeton University Press

Sugiyono. 2011. Metode Penelitian Kuantitatif , Kualitatif dan R\&D. Bandung: Alfabet. 
Atsiw Wista, “ Teori-teori Efektivitas ”, "Jadi orang PENTING itu BAIK, tapi jadi orang BAIK itu lebih PENTING", http://atsiwwista.blogspot.co.id/2013/09/teoriteoriefektivitas.html\#comment-form (diakses 1 februari 2018).

Anggraini, Susan Dwi. 2015. Pengertian Efektivitas dan Landasan Teori Efektivitas. http://literaturbook.blogspot.co.id/2014/12/pengertian-efektivitas-danlandasan.html. diakses 29 Juli 2016

Moedzakir, Djauzi. 2007, 5 Macam Tradisi Penelitian Kualitatif Malang: Universitas Negeri Malang. 